\title{
Growth of Legionella spp. under conditions of iron restriction
}

\author{
PAOLA GOLDONI,* P. VISCA, $\dagger$ MADDALENA CASTELLANI PASTORIS, PIERA VALENTI‡ \\ and N. ORSIt \\ Laboratorio di Batteriologia e Micologia Medica, Instituto Superiore di Sanità, 00161 Roma, †/stituto di Microbiologia, \\ Università di Roma "La Sapienza", 00100 Roma and ¥/stituto di Microbiologia, Università di Napoli, 80126 Napoli, \\ Italy
}

\begin{abstract}
Summary. The growth inhibiting activity of transferrins, citrate, 2-2' dipyridyl and desferrioxamine methanesulphonate towards Legionella spp. and their serogroups was investigated. The inhibitory activity of all these compounds depended upon the iron-free state of the molecules and was abolished by saturation with iron. No bactericidal effect by transferrins was observed at concentrations up to four times the minimal bacteriostatic concentration. No interaction of transferrins with the legionella cell surface was detected by direct or indirect fluorescence assay, or by dialysis culture experiments in which transferrin was separated from the bacterial cells. The demonstration of a siderophore-like activity in supernates of iron-deficient legionella cultures may account for the ability of Legionella spp. to multiply in conditions of iron restriction.
\end{abstract}

\section{Introduction}

Iron is an essential element for all forms of life, being an irreplaceable component of many enzymes, particularly those connected with respiratory chains. $^{1,2}$ The acquisition of iron by micro-organisms, in competition with the host transferrins (serum transferrin, lactoferrin, and ovotransferrin), is fundamental to the production of infection by pathogenic bacteria. ${ }^{3-5}$ Because of the extreme insolubility of ferric iron at neutral $\mathrm{pH}$, and of the low availability of free iron in the body fluids, ${ }^{6}$ most micro-organisms synthesise iron-chelating compounds called siderophores, which are excreted into the medium and taken up by cells as siderophore-Fe(III) complexes via specific receptors. ${ }^{\top}$ In a few micro-organisms, e.g., Neisseria spp., Bordetella pertussis and Haemophilus influenzae, iron acquisition has been shown to take place by direct uptake from the transferrins of the host, and not by means of siderophores. ${ }^{8-12}$ Conflicting results have been reported on the production of siderophores by Legionella spp. Warren and Miller ${ }^{13}$ stated that $L$. pneumophila produces at least two different types of catechol-like siderophore when cultured in an iron-deficient chemically defined medium, but Reeves et al. ${ }^{14}$ did not detect any production of hydroxamate or catechol-like siderophore by various species and serogroups of Legionella. Moreover it has been shown that L. pneumophila was significantly

Received 4 April 1990; accepted 3 Aug. 1990.

* Present address: Istituto di Microbiologia, Università di Roma "La Sapienza", 00100 Roma, Italy. inhibited by different iron chelators, ${ }^{15,16}$ and was sensitive to the bactericidal effect of both lactoferrin and serum transferrin. ${ }^{15,17}$

Here we report a study of the sensitivity of different Legionella spp. and serogroups to chemical and biological iron chelators and of the possible mechanisms of iron acquisition by these bacteria.

\section{Materials and methods}

\section{Bacterial strains}

The type strains of various Legionella spp. and serogroups were used: L. pneumophila serogroup 1, strain Philadelphia 1; serogroup 2, strain Togus 1; serogroup 3, strain Bloomington 2; strain Los Angeles 1, formerly described as serogroup 4; strain Dallas 1E, formerly described as serogroup 5 ; serogroup 6 , strain Chicago 2; serogroup 7, strain Chicago 8; serogroup 8, strain Concord 3; serogroup 9, strain IN-23-G1-C2; serogroup 10, strain Leiden $1 ;$ L. micdadei strain Tatlock; L. bozemanii serogroup 2, strain Toronto 3; $L$. dumoffii, strain NY $/ 23 ; L$. jordanis, strain B/540; $L$. oakridgensis, strain OR-10. An additional clinical isolate of $L$. pneumophila serogroup 6, strain Monza $3 / 1386,{ }^{18}$ which was subcultured only twice after isolation, was used for some assays. All type strains were stored as stock cultures at $-70^{\circ} \mathrm{C}$ in skimmed milk, and maintained on Buffered Charcoal-Yeast Extract Agar with $\alpha$-ketoglutarate $0.1 \%$ (BCYE- $\alpha$ agar, Oxoid). ${ }^{19}$ The recent clinical isolate of $L$. 
pneumophila serogroup 6 was stored at $-70^{\circ} \mathrm{C}$ in skimmed milk, and subcultured once for use.

\section{Media and culture conditions}

Buffered Yeast Extract (BYE) broth was prepared with yeast extract (Difco) $10 \mathrm{~g} / \mathrm{L}$ supplemented with ACES buffer (Sigma) $10 \mathrm{~g} / \mathrm{L}, \mathrm{pH} 7 \cdot 0$, L-cysteine hydrochloride (BDH Chemicals Ltd, Poole) $400 \mathrm{mg} / \mathrm{L}$ and $\alpha$-ketoglutarate (Sigma) $1 \mathrm{~g} / \mathrm{L}$. A liquid chemically defined medium (CDM) was prepared according to Reeves et al. ${ }^{14}$ The iron concentration, as determined by atomic absorption spectrophotometry, was $27 \mu \mathrm{M}$ in BYE broth and $20 \mu \mathrm{M}$ in CDM. In experiments for siderophore detection, the iron concentration in both media was reduced by omitting ferrous sulphate from the CDM and by treating the BYE broth with the iron-chelating resin Chelex 100 (Biorad Laboratories, Richmond, Ca, USA) $5 \mathrm{mg} / \mathrm{ml}$, for $24 \mathrm{~h}$ at $4^{\circ} \mathrm{C}$. In the case of the latter treatment it must be considered that other ions, such as $\mathrm{Mg}$ (II), $\mathrm{Ca}$ (II), $\mathrm{Cu}$ (II), $\mathrm{Mn}$ (II) etc., in addition to iron might have been removed. Plate counts were performed on BCYE- $\alpha$-agar. A growth temperature of $36^{\circ} \mathrm{C}$ was used for cultures in both liquid and solid media; plates were incubated in air in a moist atmosphere.

\section{Transferrins}

Apo-transferrin (Tf) from human serum and apolactoferrin (Lf) from human colostrum were obtained from Sigma; apo-ovotransferrin (Otf) was kindly supplied by the Department of Biochemistry of the University of Rome "La Sapienza". The purity of Tf and $L f$ was checked by discontinuous sodium dodecyl sulphate-polyacrylamide gel electrophoresis, ${ }^{20}$ and the preparations of Otf were characterised by electrophoresis, analytical ultracentrifugation and iron-binding capacity. ${ }^{21,22}$ In control experiments, iron-saturated transferrins $\mathrm{s}^{23}$ were also used. Fluorescein-conjugated Otf was prepared by us with fluorescein-isothiocyanate (Isomer IV; Sigma). ${ }^{24}$ For the experiments, transferrins were prepared by dilution of a $266 \mu \mathrm{M}$ stock solution in phosphate-buffered saline (PBS) containing $50 \mathrm{~mm}$ sodium bicarbonate ( $\mathrm{pH} \mathrm{7.0)}$ to generate ironbinding function and sterilised by membrane filtration (Millipore SpA, Rome, Italy), $0.45-\mu \mathrm{m}$ pore size. The antibacterial activity of transferrin preparations was controlled in all the experiments with a sensitive strain (803) of Escherichia coli $\mathrm{K}-12 .{ }^{23}$

\section{Chelating agents}

2-2' Dipyridyl (Sigma), sodium citrate (Merck, Darmstadt, FRG) and desferrioxamine methanesulphonate (DSF) (Desferal; Ciba-Geigy, Basel, Switzerland) were used as chemical chelators. Stock aqueous solutions, at 10 times the required final concentration, were sterilised by membrane filtration (Millipore), $0 \cdot 45-\mu \mathrm{m}$ pore size.

\section{Growth inhibition assay}

L. pneumophila strains were tested for their sensitivity to iron chelators in microtitration plates. Serial two-fold dilutions of the chelator were made in BYE broth and in CDM. The inoculum was prepared from a 96-h culture in iron-free CDM and consisted of c. $10^{4} \mathrm{cfu}$ in $200 \mu \mathrm{l}$ of CDM/well. For other Legionella spp., which grew very poorly in CDM, the growth inhibition assay was performed in BYE broth only. For this purpose, 72-h cultures on BCYE- $\alpha$-agar were washed twice in sterile distilled, deionised water, being held at $36^{\circ} \mathrm{C}$ for $1 \mathrm{~h}$ on each occasion before centrifugation, and then adjusted to the concentration indicated above before use as inocula. The ironbinding agents were added just before the bacterial suspensions and the microtitration plates were incubated at $36^{\circ} \mathrm{C}$ with moderate agitation. Experiments were performed in triplicate. The activity of chelators was expressed as the minimal concentration inhibiting bacterial growth after incubation for $72 \mathrm{~h}\left(\mathrm{~A}_{620}\right.$ of the cultures $<0 \cdot 100$ ).

\section{Bactericidal activity assay}

The tests were performed in duplicate in microtitration plates with the following strains: $L$. pneumophila serogroups 1 and 8 (reference strains); L. pneumophila serogroup 6, strain Monza 3/1386; L. dumoffii (a nonpneumophila species). Cultures grown for $72 \mathrm{~h}$ on BCYE agar were twice washed in sterile distilled, deionised water, being held at $36^{\circ} \mathrm{C}$ for $1 \mathrm{~h}$ on each occasion before centrifugation and resuspension to a density of 4 (McFarland turbidity standard; $c .10^{9} \mathrm{cfu} /$ $\mathrm{ml})$. Doubling dilutions of the stock transferrin solutions (Tf, Lf, Otf) were prepared in sterile distilled, deionised water to give final dilutions from 106.66 to $6.66 \mu \mathrm{M}$. The inoculum was then added to a final concentration of $10^{5} \mathrm{cfu} / \mathrm{ml}$. The number of viable cells was checked by plating dilutions of the bacterial suspensions immediately and after incubation at $36^{\circ} \mathrm{C}$ for $2 \mathrm{~h}$.

\section{Fluorescent staining assays}

Direct fluorescence (DF) or indirect immunofluorescence (IF) assays were performed to detect a possible interaction between transferrins and the bacterial surface. Experiments were performed with $L$. pneumophila serogroups 1,4 and $8, L$. dumoffii, $L$. micdadei, and $L$. oakridgensis in suspension or fixed by different methods and satisfactory observations were obtained as follows. Legionella cells grown on BCYE$\alpha$-agar were washed once, resuspended in PBS, $\mathrm{pH} 7 \cdot 2$, and distributed on multiwell microscope slides (500600 organisms/field). After heat-fixation, slides were immersed in formalin $10 \%$ for $10 \mathrm{~min}$ at room temperature, washed and air-dried. The DF assay was performed for Otf. A solution of fluorescein isothiocyanate-conjugated apo-Otf(FITC-Otf), $2 \mathrm{mg} / \mathrm{ml}$, was 
dropped on to the slides before incubation at $36^{\circ} \mathrm{C}$ for up to $3 \mathrm{~h}$ in a moist chamber. After washing with PBS, slides were mounted with buffered glycerol, $\mathrm{pH} \mathbf{9 \cdot 0}$, and examined under UV light. The IF assay was performed for Tf and Lf. Slides were prepared and fixed as described above; transferrins $(1 \mathrm{mg} / \mathrm{ml} ; 5-\mu \mathrm{l}$ volumes) were distributed into the wells and the slides were incubated for up to $3 \mathrm{~h}$ at $36^{\circ} \mathrm{C}$. The preparations were then rinsed with PBS, placed in a PBS bath for $5 \mathrm{~min}$, and air-dried. Tf goat antiserum and $\mathrm{Lf}$ rabbit antiserum (Sigma) were distributed into the appropriate wells $(5-\mu 1$ volumes of a $1: 8$ dilution), incubated for $2 \mathrm{~h}$ at $36^{\circ} \mathrm{C}$, and washed twice with PBS. FITCanti-goat immunoglobulin (Cappel Organon Teknika Corp., PA, USA; dilution 1:10) and FITC-anti-rabbit immunoglobulin (Wellcome Research Laboratories, Beckenham; dilution 1:50) were then used for staining the preparations. After incubation for $30 \mathrm{~min}$ at $36^{\circ} \mathrm{C}$ the slides were washed, mounted with buffered glycerol, pH 9.0, and observed under UV light. As a positive control, the sensitive E. coli strain 803 was used in DF experiments.

\section{Dialysis cultures}

L. pneumophila serogroup 1 and the recent clinical isolate of $L$. pneumophila serogroup 6 were used in experiments with apo- and iron-saturated Otf. Either $1 \mathrm{ml}$ of $266-\mu \mathrm{M}$ Otf in $50 \mathrm{mM}$ sodium bicarbonate,

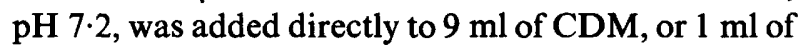
$266 \mu \mathrm{M}$ Otf was enclosed in a dialysis bag and immersed in a tube $(180 \mathrm{~mm} \times 20 \mathrm{~mm}$, iron-free) containing $9 \mathrm{ml}$ of CDM to separate it from culture medium. Tubes were inoculated with $100-\mu l$ volumes of bacterial suspensions $\left(c .10^{8} \mathrm{cfu} / \mathrm{ml}\right)$ in iron-free CDM.

\section{Siderophore assay}

Tests for siderophore detection were performed on culture supernates of all $L$. pneumophila strains grown in "iron-free" CDM ( $\mathrm{Fe}$ concentration $0.05 \mathrm{ppm}$, determined by atomic absorption spectrophotometry) with or without $100 \mu \mathrm{M}$ ferrous sulphate. Bacteria from a 96-h culture in CDM were washed twice in distilled, deionised water as described above, and $5 \times 10^{5} \mathrm{cfu}$ were used to inoculate $200 \mathrm{ml}$ of medium either in 250$\mathrm{ml}$ or 500-ml Erlenmeyer flasks. Cultures were grown in aerated conditions with vigorous agitation of the 500 -ml flasks at $250 \mathrm{rpm}$ in a G25 orbital shaker (New Brunswick) and in non-aerated static cultures in sealed 250-ml flasks. Legionella spp. other than L. pneumophila were grown in Chelex 100-treated BYE broth (Fe concentration $0.33 \mathrm{ppm}$ ). At $24-\mathrm{h}$ intervals samples of culture were examined for optical density at $620 \mathrm{~nm}$ and for siderophore activity in the supernate. The presence of catechol-like siderophores was identified by the Arnow assay ${ }^{25}$ with 2,3-dihydroxybenzoic acid as standard; enterochelin produced by E. coli 803 was used as a positive control. For the determination of hydroxamate-like siderophores a modification of the Csàky test ${ }^{26}$ proposed by Gibson and Magrath ${ }^{27}$ was employed; aerobactin produced by Enterobacter aerogenes 62-1 was used as a positive control. In addition, iron-binding compounds were detected by the method proposed by Schwyn and Neilands. ${ }^{28}$ In all tests for siderophores the uninoculated medium was used as a control. Glassware was washed in $0.1 \mathrm{M} \mathrm{HCl}$, and rinsed with double-distilled water. To express siderophore activity, serial dilutions of DSF were used as standards.

\section{Results}

\section{Sensitivity of Legionella spp. to iron chelators}

Serial two-fold dilutions of chelating agents with different affinities for iron were used in the following concentration ranges: sodium citrate $136-4.25 \mathrm{mM}, 2-$ 2 ' dipyridyl and DSF 512-16 $\mu \mathrm{M}$, and transferrins (Tf, Lf, Otf) $53.33-1.66 \mu \mathrm{M}$. In this test, L. pneumophila strains were grown in CDM and other Legionella spp. were grown in BYE broth.

Results obtained after incubation for $72 \mathrm{~h}$ are reported in the table. Little variation was found between strains in their sensitivity to sodium citrate, $2-2^{\prime}$ dipyridyl and transferrins. Only minor differences were apparent between $L$. pneumophila and other Legionella spp. except with DSF. The differences seen with this substance may have been due to the complex

Table. Minimal inhibitory concentrations of transferrins and chelators for L. pneumophila strains and other Legionella spp.

\begin{tabular}{|c|c|c|c|c|c|c|}
\hline \multirow{3}{*}{$\begin{array}{l}\text { Legionella } \\
\text { spp. and } \\
\text { strains }\end{array}$} & \multicolumn{6}{|c|}{ Minimal inhibitory concentration* $(\mu M)$ of } \\
\hline & \multicolumn{3}{|c|}{ transferrin } & \multicolumn{3}{|c|}{ chelator } \\
\hline & Tf & Lf & Otf & $\begin{array}{c}\text { Citrate } \dagger \\
\left(10^{3}\right)\end{array}$ & DSF & DPD \\
\hline \multicolumn{7}{|l|}{ L. pneumophila } \\
\hline Philadelphia 1 & $26 \cdot 6$ & $13 \cdot 3$ & $26 \cdot 6$ & $8 \cdot 5$ & 32 & 128 \\
\hline Togus 1 & $26 \cdot 6$ & $13 \cdot 3$ & $13 \cdot 3$ & $8 \cdot 5$ & 64 & 128 \\
\hline Bloomington 2 & $13 \cdot 3$ & $13 \cdot 3$ & $13 \cdot 3$ & $17 \cdot 0$ & 64 & 256 \\
\hline Los Angeles 1 & $26 \cdot 6$ & $13 \cdot 3$ & $13 \cdot 3$ & $17 \cdot 0$ & 32 & 256 \\
\hline Dallas 1E & $26 \cdot 6$ & $13 \cdot 3$ & $13 \cdot 3$ & $17 \cdot 0$ & 64 & 256 \\
\hline Chicago 2 & $26 \cdot 6$ & $26 \cdot 6$ & $26 \cdot 6$ & $17 \cdot 0$ & 64 & 256 \\
\hline Chicago 8 & $26 \cdot 6$ & $13 \cdot 3$ & $26 \cdot 6$ & $8 \cdot 5$ & 32 & 256 \\
\hline Concord 3 & $26 \cdot 6$ & $13 \cdot 3$ & $26 \cdot 6$ & $8 \cdot 5$ & 64 & 256 \\
\hline IN-23-G1-C2 & $13 \cdot 3$ & $13 \cdot 3$ & $13 \cdot 3$ & $8 \cdot 5$ & 32 & 128 \\
\hline Leiden 1 & $26 \cdot 6$ & $13 \cdot 3$ & $26 \cdot 6$ & $17 \cdot 0$ & 32 & 256 \\
\hline L. bozemanii & $53 \cdot 3$ & $26 \cdot 6$ & $26 \cdot 6$ & $34 \cdot 0$ & 512 & 256 \\
\hline L. dumoffii & $26 \cdot 6$ & $13 \cdot 3$ & $26 \cdot 6$ & $34 \cdot 0$ & 512 & 256 \\
\hline L. jordanis & $26 \cdot 6$ & $13 \cdot 3$ & $26 \cdot 6$ & $68 \cdot 0$ & 512 & 256 \\
\hline L. oakridgensis & $26 \cdot 6$ & $13 \cdot 3$ & $26 \cdot 6$ & $34 \cdot 0$ & 512 & 256 \\
\hline L. micdadei & $53 \cdot 3$ & $26 \cdot 6$ & $53 \cdot 3$ & $34 \cdot 0$ & 512 & 256 \\
\hline
\end{tabular}

* Minimal inhibitory concentrations gave $\mathrm{A}_{620}<0.100$ after incubation of the culture at $36^{\circ} \mathrm{C}$ for $72 \mathrm{~h}$.

$\dagger$ Citrate as $\mathrm{Na}_{3} \mathrm{C}_{6} \mathrm{H}_{5} \mathrm{O}_{7} .2 \mathrm{H}_{2} \mathrm{O}$.

DSF, desferrioxamine methanesulphonate; DPD, 2-2' dipyridyl. 
and ill-defined composition of the BYE broth used for the non-pneumophila species, which grew very poorly in CDM. When all the L. pneumophila strains were grown in BYE broth they gave DSF inhibition values similar to those of other Legionella spp. (data not shown).

The inhibitory activity of the chelators and transferrins was completely suppressed by pre-incubation with equimolar amounts of ferric chloride before adding the bacteria.

To determine whether the inhibitory activity of transferrins was solely bacteriostatic or in part bactericidal, a bactericidal activity assay was performed with some strains of Legionella. The bacteria were suspended in sterile distilled, deionised water and kept in contact with transferrins at concentrations of 106.66-6.66 $\mu \mathrm{M}$ for $2 \mathrm{~h}$. No bactericidal activity was detected for concentrations at least four times as great as the minimal inhibitory concentrations reported in the table. The bacteria employed in all growth inhibition assays, including tests for bactericidal activity, underwent prolonged $(2 \mathrm{~h})$ washing in sterile distilled, deionised water to avoid the carry-over of small quantities of iron from the cultures from which they were derived.

\section{"Interaction tests" with dialysis cultures and fluorescent staining}

These experiments were performed to determine whether transferrins act on legionellae only as chelating agents, i.e., without any interaction with the bacterial surface, or require direct contact with the cells for their antibacterial action. The experiments were performed with legionellae either kept in contact with Otf or separated from it by a dialysis membrane; $53.3 \mu \mathrm{M}$ Otf produced the same degree of growth inhibition, regardless of whether it was in direct contact or was separated from the bacterial cells by a dialysis membrane. Under both conditions, iron-
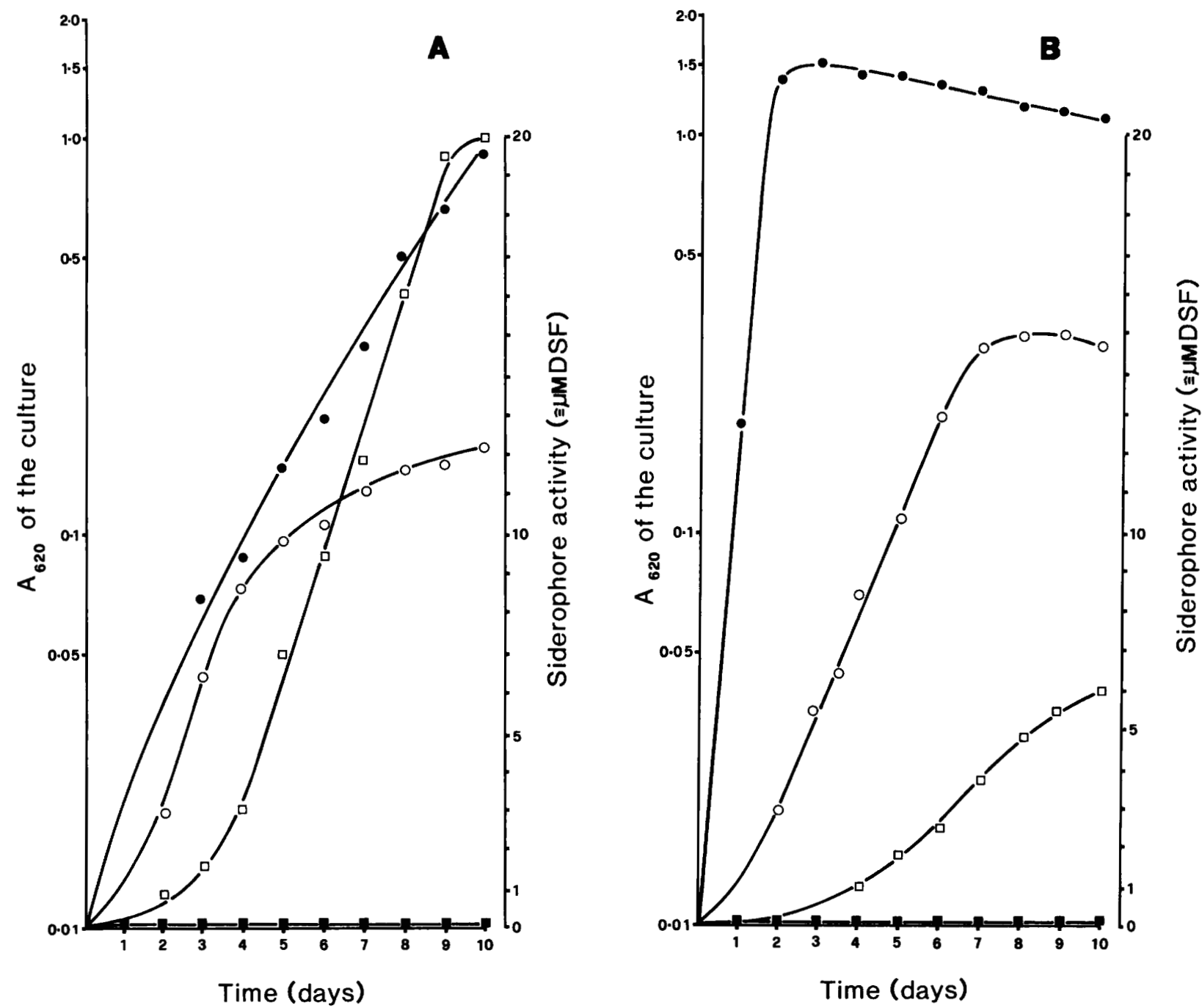

Figure. Growth of $L$. pneumophila Philadephia 1 and production of siderophore-like activity in static (A) and aerated (B) cultures. $O, A_{620}$ of culture in iron-free CDM;, $\mathrm{A}_{620}$ of culture in CDM supplemented with $100 \mu \mathrm{M}$ iron; $\square$ siderophore activity, corresponding to ( $\left.\hat{=}\right)$ $\mu \mathrm{MDSF}$, in iron-free CDM culture supernates. Siderophore activity in supernate of culture in CDM supplemented with $100 \mu \mathrm{M}$ iron (mean values from duplicate tests). Data shown from one of three separate experiments. 
saturated Otf caused no inhibition and permitted growth similar to that of the control culture in CDM without Otf.

The lack of interaction between transferrins and the legionella surface was confirmed by DF and IF assays; negative results in tests for the presence of transferrins on the bacterial surface were obtained with bacteria both in suspension and fixed by different methods.

\section{Production of siderophores}

Siderophore activity was investigated in both static and aerated cultures of different strains of $L$. pneumophila. The figure shows the growth curves of $L$. pneumophila strain Philadelphia 1 in static and aerated conditions, and the siderophore activity measured by the assay of Schwyn and Neilands. ${ }^{28}$ Parallel cultures were set up in "iron-free" CDM (0.05 ppm of iron) and in CDM supplemented with $100 \mu \mathrm{M}$ iron, and growth was monitored for up to 10 days. The results show that, with aeration, growth was much more luxuriant in iron-supplemented than in iron-free culture medium, whereas in static cultures the converse was true. It is possible that oxygen toxicity is enhanced during iron-deficient culture, when the activity of various oxygen detoxifying iron-containing enzymes has declined. ${ }^{2}$

With or without aeration, siderophore activity appeared in the cultures after incubation for 3-4 days, i.e., during the logarithmic growth phase, and reached its maximum at the stationary phase; maximum activity was consistently higher in static than in aerated cultures. Supplementation of CDM with $100 \mu \mathrm{M}$ iron completely suppressed synthesis of the substances responsible for the positive reaction in the Schwyn and Neilands test. ${ }^{28}$ Siderophore activity was produced by all eight $L$. pneumophila serogroups examined; however, for some strains, aeration of the culture did not favour bacterial growth and this prevented the demonstration of siderophore activity. However, activity was demonstrated in supernates of cultures of $L$. micdadei, $L$. bozemanii, $L$. dumoffii, $L$. jordanis and L.oakridgensis grown for 6 days in Chelex 100-treated BYE broth; it was abolished by the addition of $100 \mu \mathrm{M}$ iron to the growth medium. It must be pointed out that, for all samples that gave positive results in the Schwyn and Neilands test, ${ }^{28}$ the Arnow test $^{25}$ for catechols and the Csàky assay ${ }^{26}$ for hydroxamates gave negative results.

\section{Discussion}

The results demonstrate that iron-binding compounds (transferrins, and chemical and siderophorelike chelators) inhibit the growth of various Legionella spp. and serogroups. Because no standard protocol for the assessment of the activity of iron-binding compounds has been established, the experiments were made in CDM for L. pneumophila, and in BYE broth for non-pneumophila species. The iron concentration in CDM and BYE broth corresponded to $20 \mu \mathrm{M}$ and $27 \mu \mathrm{M}$ respectively. The growth-inhibiting activity of the chelators tested depended on the abolition of their iron-free state by saturation with $\mathrm{Fe}(\mathrm{III})$. The effect of all the chelators was bacteriostatic within wide concentration ranges but not bactericidal. Thus, the results conflict with previous reports, ${ }^{15,17}$ which suggested that transferrins ( $T f$ and $L f$ ) and other iron chelators such as 1-10 phenanthroline and desferrioxamine B had bactericidal activity. In our in-vitro test, we did not observe any bactericidal effect of chelators that included Lf, Tf and Otf. However, this result does not exclude the possibility that there may be a bactericidal effect in vivo when transferrins in the apo or partly saturated form interact with other host defence proteins such as antibodies ( $\operatorname{IgA})$ and complement. It must also be borne in mind that any possible short-term bactericidal action of transferrins could not be simply ascribed to the iron-chelating activity but would also depend on direct interaction with the microbial surface. ${ }^{17,29,30}$ In the present experiments, the observed lack of bactericidal activity of transferrins was supported by the results of DF and IF assays, which did not show any binding of transferrins ( $\mathrm{Tf}, \mathrm{Lf}$ and Otf) to the cell surface of legionellae. The experiments with dialysis membrane separation showed that the bacteriostatic activity of transferrin was the same, regardless of whether it was free in the culture medium or separated from the bacteria. For micro-organisms interacting directly with transferrin, the antimicrobial activity is enhanced by direct contact and dramatically reduced by separation from the bacterial cells. Our results indicate that transferrins do not interact directly with the legionella surface. The transferrin preparations were free from iron and contaminating protein.

The capacity of Legionella spp. to grow under irondeficient conditions, e.g., those occurring in the presence of sub-bacteriostatic amounts of chelators, has been related to siderophore-like activity. In the experiments described, all $L$. pneumophila serogroups tested, as well as other Legionella spp., produced substances with siderophore-like activity when cultured under conditions of iron restriction; this activity was completely suppressed in iron-rich cultures.

The siderophore-like activity of Legionella spp. has been demonstrated by the siderophore-specific universal chemical assay of Schwyn and Neilands. ${ }^{28} \mathrm{Nega-}$ tive reactions with the Arnow test ${ }^{25}$ and the Csàky test excluded catechols and hydroxamates, ${ }^{26}$ respectively, as the siderophore-like compounds. However, several siderophores are known to be neither hydroxamates nor catechols. ${ }^{28,31}$ Previous conflicting results ${ }^{13,14}$ should be reconsidered in the light of the methods used at the time. Further studies are required to determine the chemical and biological properties of the substances responsible for siderophore-like activity in Legionella spp. These substances, like microbial 
siderophores in general, were produced only in the absence of iron. The concentration of iron in CDM was too low $(0.05 \mathrm{ppm})$ to allow acquisition by a low affinity system; therefore, it may be argued that the growth of $L$. pneumophila in this medium occurred only by means of a high affinity system.

The production of siderophores in response to iron restriction is necessary for the growth of most microorganisms; this may be taken to include Legionella spp., in view of their iron requirements and the aerophilic nature of their metabolism. ${ }^{16,32}$ Legionella spp. occur in natural aquatic environments, at a $\mathrm{pH}$ close to neutrality $(5 \cdot 4-8 \cdot 1)^{33}$, that contain extremely low amounts of soluble trace metals and are unable to support survival and growth in the absence of any iron-solubilising agent. In legionella infection, hypoferraemia and hypertransferrinaemia have been shown to act as host defence mechanisms. ${ }^{34}$

In conclusion, Legionella spp., like most microorganisms, can grow under conditions of iron restriction by synthesising chelators; they also show an overall sensitivity to iron-binding agents similar to that observed for several gram-negative bacteria. ${ }^{22,23}$

\section{References}

1. Lankford CE. Bacterial assimilation of iron. Crit Rev Microbiol 1973; 2: 273-331.

2. Neilands JB. Microbial iron metabolism: a comprehensive treatise. New York, Academic Press 1974.

3. Bullen JJ. The significance of iron in infection. Rev Infect Dis $1981 ; 3: 1127-1138$.

4. Weinberg ED. Iron and infection. Microbiol Rev 1978; 42: 4566.

5. Weinberg ED. Iron withholding: a defense against infection and neoplasia. Physiol Rev 1984; 64: 65-102.

6. Griffiths E. Iron in biological systems. In: Bullen JJ, Griffiths E (eds) Iron and infection. Chichester, John Wiley and Sons. 1987: 1-25.

7. Winkelmann G, Van Der Helm D, Neilands JB. Iron transport in microbes, plants and animals. Weinheim, FRG, VCH. 1987.

8. Archibald FS, De Voe IW. Removal of iron from human transferrin by Neisseria meningitidis. FEMS Microbiol Lett 1979; 6: 159-162.

9. Herrington DA, Sparling PF. Haemophilus influenzae can use human transferrin as a sole source of required iron. Infect Immun 1985; 48: 248-251.

10. Mickelsen PA, Blackman E, Sparling PF. Ability of Neisseria gonorrhoeae, Neisseria meningitidis, and commensal Neisseria species to obtain iron from lactoferrin. Infect Immun $1982 ; 35$ : 915-920.

11. Mietzner TA, Luginbuhl GH, Sandstrom E, Morse SA. Identification of iron-regulated 37,000-dalton protein in the cell envelope of Neisseria gonorrhoeae. Infect Immun $1984 ; 45: 410-416$.

12. Redhead $\mathrm{K}$, Hill $\mathrm{T}$, Chart $\mathrm{H}$. Interaction of lactoferrin and transferrins with the outer membrane of Bordetella pertussis. J Gen Microbiol 1987; 133: 891-898.

13. Warren WJ, Miller RD. Abstracts of the Annual Meeting of the American Society for Microbiology, D67. 1980: 49.

14. Reeves MW, Pine L, Neilands JB, Balows A. Absence of siderophore activity in Legionella species grown in irondeficient media. J Bacteriol 1983; 154: 324-329.

15. Quinn FD, Weinberg ED. Killing of Legionella pneumophila by human serum and iron-binding agents. Curr Microbiol 1988; 17: 111-116.

16. Reeves MW, Pine L, Hutner SH, George JR, Harrell WK. Metal requirements of Legionella pneumophila. J Clin Microbiol 1981; 13: 688-695.

17. Bortner CA, Miller RD, Arnold RR. Bactericidal effect of lactoferrin on Legionella pneumophila. Infect Immun 1986; 51: 373-377.

18. Viganò EF, Giltri G, Cappellini A, Brenna A, Catellani Pastoris M. Polmonite nosocomiale infausta da Legionella pneumophila sierogruppo 6. In: Microbiologia della infezioni ospedaliere. XVIII Congresso Nazionale Associazione Microbiologi Clinici Italiani. Rome, 8-11 November 1989: 121.

19. Edelstein PH. Improved semiselective medium for the isolation of Legionella pneumophila from contaminated clinical and environmental specimens. J Clin Microbiol 1981; 14: 298303.

20. Ellison RT, Giehl TJ, LaForce MF. Damage of the outer membrane of enteric gram-negative bacteria by lactoferrin and transferrin. Infect Immun 1988; 56: 2774-2781.

21. Phelps CF, Antonini E. A study on the kinetics of iron and copper binding to hen ovotransferrin. Biochem $J$ 1975; 147: $385-391$.

22. Valenti P, Antonini G, von Hunolstein C, Visca P, Orsi N, Antonini E. Studies on the antimicrobial activity of ovotransferrin. Int J Tissue React 1983; 1: 97-105.

23. Valenti $P$, Visca $P$, Antonini $G$, Orsi $N$, Antonini $E$. The effect of saturation with $\mathrm{Zn}^{2+}$ and other metal ions on the antibacterial activity of ovotransferrin. Med Microbiol Immunol (Berl) 1987; 176: 123-130.

24. Wood JN. Immunofluorescence and immunoperoxidase screening of hybridomas. In: Walker JM (ed) Methods in molecular biology, vol 1, Proteins. Clifton, NJ, Humana Press. 1984: 271-278.

25. Arnow LE. Colorimetric determination of the components of 3,4-dihydroxyphenylalanine-tyrosine mixtures. J Biol Chem 1937; 118: 531-537.

26. Csàky TZ. On the estimation of bound hydroxylamine in biological materials. Acta Chem Scand 1948; $2: 450-454$.

27. Gibson F, Magrath DI. The isolation and characterization of a hydroxamic acid (aerobactin) formed by Aerobacter aerogenes 62-1. Biochim Biophys Acta 1969; 192: 175-184.

28. Schwyn B, Neilands JB. Universal chemical assay for the detection and determination of siderophores. Anal Biochem $1987 ; 160$ : 47-56.

29. Arnold RR, Cole MF, McGhee JR. A bactericidal effect for human lactoferrin. Science 1977; 197: 263-265.

30. Arnold RR, Brewer M, Gauthier JJ. Bactericidal activity of human lactoferrin; sensitivity of a variety of microorganisms. Infect Immun 1980; 28: 893-898.

31. Neilands JB. Methodology of siderophores. Struct Bond 1984; 58: 1-24.

32. Pine L, George JR, Reeves MW, Harrell E. Development of a chemically defined liquid medium for the growth of Legionella pneumophila. J Clin Microbiol 1979; 9:615-626.

33. Fliermans CB, Cherry WB, Orrison LH, Smith SJ, Tison DL, Pope DH. Ecological distribution of Legionella pneumophila. Appl Environ Microbiol 1981; 41: 9-16.

34. Muller D, Edwards ML, Smith DW. Changes in iron and transferrin levels and body temperature in experimental airborne legionellosis. J Infect Dis 1983; 147: 302-307. 